Article

\title{
Evaluating the Multi-Functionality of Forest Ecosystems in Northern Mexico
}

\author{
Gustavo Perez-Verdin ${ }^{1, *(1)}$, Jose Carlos Monarrez-Gonzalez ${ }^{1}$, Aregai Tecle ${ }^{2}$ and \\ Marin Pompa-Garcia 3 (iD) \\ 1 Instituto Politecnico Nacional, CIIDIR Durango, Sigma 119, 34233 Durango, Mexico; \\ monarrez.josecarlos@gmail.com \\ 2 School of Forestry, Northern Arizona University, P.O. Box 15018, Flagstaff, AZ 86011, USA; \\ Aregai.Tecle@nau.edu \\ 3 Escuela de Ciencias Forestales, Universidad Juarez de Durango, Rio Papaloapan, Valle del Sur, \\ 34120 Durango, Mexico; mpgarcia@ujed.mx \\ * Correspondence: guperezv@ipn.mx; Tel.: +52-618-814-2091
}

Received: 2 March 2018; Accepted: 23 March 2018; Published: 2 April 2018

\begin{abstract}
Managing multiple ecosystem services is a complex task that involves special interactions among different resources, services, and stakeholders. Mexican forests have been traditionally managed for the single purpose of obtaining wood, benefiting a small sector of society. In this study, we evaluated the interactions among various ecosystem services, namely carbon content, tree diversity, surface water runoff, and the net present value of timber production. We also attempted to determine the most suitable basal area level that best satisfies the management of these services combined. Bivariate correlations, non-linear regression models, and a multiobjective decision-making technique are used to analyze the data in the study. Results indicate that trade-offs exist between surface water runoff and tree basal area. A synergistic relationship, between net present value and carbon content with basal area, was also observed. Tree diversity has a synergistic relationship with basal area in open forests, but a trade-off relationship in denser forests. The most preferred forest management level that satisfies the desired ecosystem services is between 17 and $21 \mathrm{~m}^{2} /$ ha of residual basal area. We hope that adopting this multiobjective study can cement collaborative strategies among Mexican resource managers, landowners, environmental groups, and others interested in forest management.
\end{abstract}

Keywords: compromise programming; ecosystem services; multiobjective forest management; synergies; trade-offs

\section{Introduction}

Ecosystem services are a set of benefits that nature provides for society, either at a specific or general level, and directly dependent on the healthy functioning of ecosystems [1,2]. Ecosystems like forests, grasslands, croplands, coastal zones, and urban areas offer different services to society. These include provisioning, regulating, and cultural services that directly affect people [1]. In addition to direct and indirect uses, forests provide a variety of benefits that are classified as passive and by merely existing become valuable to society [3]. However, Mexican decision-makers are not focusing on many of these benefits because they do not generate direct or immediate profits [4,5]. The traditional approach to forest management, based primarily on timber production, does not consider the inclusion of regulating and cultural services, as well as their interactions. This single-objective management eventually leads to the degradation of some forest services, such as water flow regulation, soil erosion control, and biodiversity protection, among others [6-8]. 
The complex interactions between ecosystem services can be classified into three categories: trade-off, synergy, and no-effect $[9,10]$. Trade-offs occur when the provision of an ecosystem service increases at the expense of a simultaneous decline of another service at the same location [10]. Trade-offs exist not only between different ecosystem services, but also within the same service at different times [11]. The term synergy refers to a situation when two services can affect each other positively in the same direction resulting in a win-win relationship [12]. For example, an increase in biomass usually results in an increase of carbon content. The no-effect relationship occurs when there is no interaction between services [9]. Although it has been suggested that the compensation relationship is evidence of inefficient and sub-optimal solutions [13], this type of relationship in forest ecosystems is frequent and (to a certain extent) an explicit choice [14].

Historically, the management of forest resources in Mexico has been oriented towards the production of timber or fiber without considering its effects in other resources. This type of management tends to benefit only a small portion of society. However, forests have the capacity to produce more than one benefit at the same time, which can be useful to a broader part of society. With proper management, forests can generate the required biomass to increase $\mathrm{CO}_{2}$ absorption, improve habitats for flora and fauna, prevent water quality degradation, reduce forest fires, and decrease levels of soil erosion, among others. This type of management can be handled through multiobjective or multicriteria decision-making techniques, which also consider the opinions of stakeholders such as forest managers, government agencies, society, non-government organizations (NGOs), as well as those in the forest industry $[5,15]$.

Compromise programming is among the various multiobjective decision-making techniques found in literature [16,17]. It poses that the most preferred solution for a problem that simultaneously involves two or more objectives is the one closer to an ideal point. Such a solution is referred to as a non-dominated or Pareto efficient solution $[16,18]$. In this method, there is no single solution that simultaneously optimizes each objective. As a result, several solutions can be undertaken at the same time. A non-dominated or Pareto solution entails that no other allocation of resources could make at least one objective better off without making any other(s) worse off [19].

Based on this background, the objectives were as follows: (i) evaluate the interactions among four ecosystem services, including carbon content, tree diversity, surface water runoff, and net economic present value of timber production; and (ii) to solve a multiobjective forest management problem consisting of these ecosystem services as well as the stakeholders' opinions. In the first objective, bivariate correlations and regression models were adjusted to explain the influence of basal area (and other dasometric variables) on a specific service (e.g., carbon content). In the second objective, the compromise programming technique was used to determine the forest management level that best satisfies the four objectives simultaneously. The study first describes the area of work, followed by details regarding the planning tool used (including the theory of ideal point). The results, discussion, and conclusions are then presented, emphasizing their implications for forest management.

\section{The Multi-Functionality of Forest Ecosystems}

Forests provide a wide diversity of ecosystem services [20-22]. Wood, fibers, clean water, food, carbon sequestration, soil fertility, and recreation are some of the many services provided by nature to society [1]. Many of these ecosystem services are not independent of each other [14]. For example, cutting off a single tree for timber has various consequences on soil retention, water infiltration, and plant diversity, among others. Due to this kind of public benefits, society plays a very important role in the way services are administered. Hence, ignoring these complex benefits and their socio-ecological interactions often results in inappropriate management practices [23].

Trade-offs, the most degradative form of ecosystem services interactions, have existed for years and occur in almost all types of ecosystems $[14,24,25]$. In the past century, an increase in provisioning services has been achieved at the expense of decreases in regulating and cultural services [1]. Trade-offs have also been the reality in the early stages of Mexican forestry [4]. Timber harvesting, which was based on intensive removal of the best trees, exerted excessive pressure on forest resources. Eventually, 
such single resource oriented management resulted in many undesired, often overexploited, forest structures and species compositions [4].

Sometimes, trade-offs are a result of explicit choices, where the loss of one benefit is balanced by the gain of another. However, in many other cases, they may happen without planning or even awareness of their occurrence [14]. Society does not have any problem with trade-offs resulting from planned actions. However, a large number of trade-off cases fall into the second category [26]. In fact, the occurrence of unintentional trade-offs has been one of the main reasons for which the Millennium Ecosystem Assessment (MEA) group has supported the application of economic valuation studies to determine the value of ecosystem services losses $[14,26]$.

Due to the diverse interactions (trade-offs, synergies) and stakeholders' preferences in ecosystem services management, it would be impossible to simultaneously maximize them all in forest planning [27-29]. Thus, a type of compromise-based management is essential, particularly one where all interactions are addressed and objectives are weighted based on the stakeholders' preferences [28]. In this case, compromise implies an "effort to approach or emulate the ideal solution as closely as possible" [16].

Recognizing the multi-functionality of forest ecosystems is the departure point of this work. We evaluated the type of relationship between various ecosystem services in an attempt to solve a forest management problem while considering the stakeholders' opinions. We expect that this study's results can raise the level of awareness among Mexican forest managers and policy-makers on the complex interactions related to ecosystem services. We also hope that this information can be considered in future forest management planning and decision-making.

\section{Material and Methods}

The study area is located in the Sierra Madre Occidental in the northwestern part of Mexico. This neo-volcanic mountain range extends along $1200 \mathrm{~km}$, from the western side of central Mexico to the border with the United States of America. It hosts one of the highest rates of plant diversity in the country, including pines, oaks, and other broadleaved trees [30]. The private property of Molinillos, the specific research site, has an area of 2800 ha. About $75 \%$ of this property is under timber production while the rest is dedicated to agricultural and livestock uses (Figure 1). The species composition is $57 \%$ pine, $39 \%$ oak, $3 \%$ other coniferous, and $1 \%$ other broadleaved trees. Some of the most important species are Pinus cooperi, P. durangensis, P. engelmannii, P. leiophylla, P. lumholtzii, P. teocote, Quercus rugosa, Quercus durifolia, Juniperus deppeana, and Arbutus sp. [31]. The climate is humid and semi-cold, with a temperature varying between $-3{ }^{\circ} \mathrm{C}$ and $18{ }^{\circ} \mathrm{C}$, and a mean annual temperature of $10{ }^{\circ} \mathrm{C}$. Most of the precipitation comes during the months of July through September and amounts to an annual average of $800 \mathrm{~mm}$. Winter rains make up between $5 \%$ to $10 \%$ of the annual precipitation. This research was conducted on this private property due to the owners' interest in participating in research projects in order to have more foundations for the better management of their forest resources. The property has a permanent surveillance system, which also simplifies the monitoring of the equipment and the collection of information.

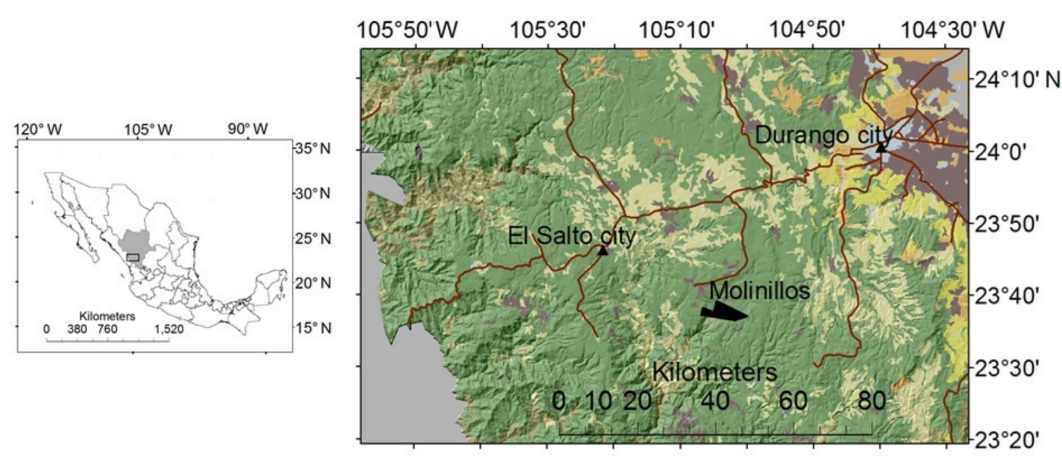

Figure 1. Location of the Molinillos private property in the state of Durango, Mexico. 


\subsection{The Theory of Ideal Point and the Compromise Programming Approach}

Consider the case of two management objectives represented graphically by the vector $(x, y)$. The ideal point represents the best performance that both objectives can separately achieve, that is, the maximum value each one can attain. However, due to many restrictive factors, such as capital, land, labor, climate, etc., it is generally impossible to achieve [16]. Usually, one objective tends to yield to the other without causing dominated solutions. Variations in the level of importance $(\lambda)$ between $0 \%$ and $100 \%$ of these objectives produce a set of compromising solutions, also known as the 'efficient frontier' or the 'Pareto frontier' $[17,32]$. The goal is to determine a point, along the efficient frontier, that turns out to be the most satisfactory solution for both objectives without having a negative outcome on either one. As shown in Figure 2, this point is the closest to the ideal point [33]. Opposite of the ideal point is the anti-ideal point, which stands for the worst possible performance of the objective. Here, any set of non-dominated solutions must be as far away from it as possible [16].

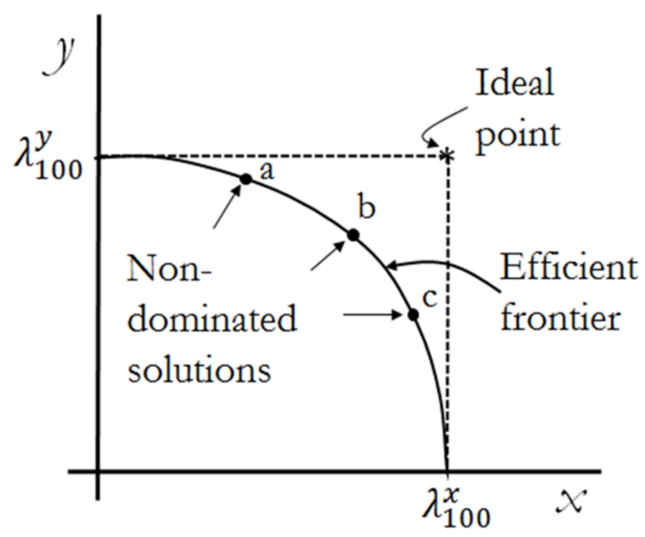

Figure 2. Representation of the ideal point, efficient frontier, non-dominated solutions, and trade-offs for two objectives. Point ' $b$ ' is the closest to the ideal point. The symbol $\lambda$ represents the level of importance for each objective. From Yu (1973) [17].

There are several ways to find a solution when two or more management objectives are involved [22], even if those are in a synergistic relationship. For instance, linear programming, and its variations integer, mixed integer, and goal programming, are based on an objective function (or various objective functions) and a series of restrictions to find an optimal solution. According to $\mathrm{Yu}$ [17] and Zeleny [16], the pioneers of the compromise programming technique, its purpose is not to find an optimal solution, but to be close to it. The reason for this is that the criteria or management objectives are usually perceived differently by different stakeholders. The objectives may be in conflict (i.e., trade-off) and it is difficult to guarantee a perfect compliance with the restrictions $[29,34]$. Unlike goal programming, the methodology based on the ideal point seeks to find a set of solutions, which are not necessarily restricted by parameters imposed by the researcher, but are the most suitable for the problem [33]. In distance-based methods, the idea of maximizing a utility function, as in classic optimization methods, is replaced by the minimization of the distance between an alternative and a target point enjoying better preferential characteristics [35]. Regardless of the methods used, it should be noted that these are only supporting tools, and their function is not to replace the role of researchers in any decision-making process [34].

In multicriteria problems that involve three or more objectives, the graphic representation of the efficient frontier or non-dominated solutions becomes more complicated to visualize. In any case, the purposes of the graphical as well as any corresponding numerical approach is to find a point of minimized distance between a set of non-dominated solutions (taken from the interaction of several objectives) and the ideal point. Compromise programming is a technique for estimating the minimum distance between the efficient frontier and the ideal point based on the level of importance assigned to 
each objective by all interested parties concerned. The measure of closeness is defined by a family of distance metrics $d_{p}$ in which any point in the objective space is a compromise solution if it satisfies the minimum distance as follows [16]:

$$
\operatorname{Min} d_{p}=\left[\sum_{i=1}^{i=I} \lambda_{i}^{p}\left(f_{i}^{*}-f_{i}\right)^{p}\right]^{1 / p}, \lambda_{i}^{p}>0, \sum_{i=1}^{i=I} \lambda_{i}^{p}=1
$$

where $p$ is a distance parameter, $f_{i}^{*}$ is the best or maximum value found for the objective $i, f_{i}$ is the estimated value of objective $i$, and $I$ is the number of objectives considered. The parameter $\lambda_{i}^{p}$ is the importance level of objective $i$.

Note that the expression $\left(f_{i}^{*}-f_{i}\right)$ in Equation (1) stands for various objectives with different units of measurement. For example, carbon content is expressed in ton/ha, water yield in $\mathrm{L} / \mathrm{ha}$, and tree diversity uses an ordinal index that does not have a unit of measurement. In order to adjust these values and eliminate the so-called incommensurability effect, the following equation was used to normalize units [29]:

$$
\varphi_{i}=\frac{f_{i}^{*}-f_{i}}{f_{i}^{*}-f_{i}^{* *}}
$$

where $f_{i}^{* *}$ represents the anti-ideal or worst value of objective $i$. In this case, Equation (1) was reduced to:

$$
\operatorname{Min} d_{p}=\left[\sum_{i=1}^{i=I} \lambda_{i}^{p} \varphi_{i}^{p}\right]^{1 / p}, \lambda_{i}^{p}>0, \sum_{i=1}^{i=I} \lambda_{i}^{p}=1
$$

The $(\varphi)$ coefficient is dimensionless and has values between 0 and 1 . With this expression, a graphic visualization of all the objectives versus basal area or other independent variable is made.

The $p$ value represents the level of importance given to the individual deviations between the ideal point and the efficient frontier. The distance for any value of $p$ (where $1 \leq p<\infty$ ) is used here as a measure to express individual preferences and not to indicate a pure geometric distance. The distance, in this case, represents risk in decision-making, comparisons, similarities, or proximity of individual coordinates $[36,37]$. However, the values most commonly used in compromise programming are $p=1$, $p=2$, and $p=\infty$ [38]. For $p=1$, all deviations from the maximum value, $f_{i}^{*}$, to the observed value of objective $i$ are given equal importance, which in a sense indicates that decision makers have low risk aversion. For $p=2$, the largest deviations are expected to exert the most influence, and as the value of $p$ increases beyond 2, there is increasingly more weight given to the largest deviation [37]. The largest geometric distance corresponds to $p=1$. This is commonly known as the Manhattan distance where $d_{p}$ turns out to be:

$$
\operatorname{Min} d_{p=1}=\left[\sum_{i=1}^{i=I} \lambda_{i}\left(\varphi_{i}\right)\right]
$$

The geometrically minimum distance between two points is a straight line; this is achieved when $p=2$ and the objective function becomes:

$$
\text { Min } d_{p=2}=\left(\sum_{i=1}^{i=I} \lambda_{i}^{2} \varphi_{i}^{2}\right)^{\frac{1}{2}}
$$

As $p$ approaches $\infty$, Equation (1) becomes a mini-max problem (minimizing the maximum distance between the efficient frontier and the ideal point), and the solution is determined as follows:

$$
\operatorname{Min} d_{p \rightarrow \infty}=\operatorname{Min} \max \left(\lambda_{i}\left(\varphi_{i}\right)\right) \forall_{i}
$$

In this technique, the sensitivity analysis is based on evaluating the deviation from the ideal point for different values of $p$ and $(\lambda)[36,38]$. 


\subsection{Evaluation of the Management Objectives}

Through 16 experimental plots, established during the period 2015-2017, the effects of several silvicultural treatments on four ecosystem services were evaluated: tree diversity, surface runoff, carbon content, and net present value of timber production. The sizes of the circular-shaped plots are 0.1 ha for trees larger than $7.5 \mathrm{~cm}$ in diameter and a sub-plot of $500 \mathrm{~m}^{2}$ for regeneration. The silvicultural treatments included thinnings (with different residual basal areas), clear-cut, and a control group. The treatments were applied following the management plan of the property, and the residual condition was evaluated after that. In the control group, no treatments were applied.

In each plot, tree diversity was estimated using the Shannon-Wiener Index, which considers the parameters of entropy and diversity in a number of existing species [39]. From among the main classes of plant diversity, which include tree, shrub, and herbaceous plants diversity, we decided to only use tree diversity. The reason for this was because it is directly and immediately modified by the application of silvicultural treatments and anthropogenic disturbances, such as legal and illegal logging, firewood harvesting, and housing construction, among others [40]. The Shannon-Wiener index $(S W I)$ for tree diversity was determined using the following equation:

$$
S W I=-\sum_{s=1}^{s=S} x_{s} \ln \left(x_{s}\right)
$$

where $S$ is the number of species and $x_{s}$ the proportion of individuals that belong to the sth species in the dataset of interest. Since the index is not itself a true diversity index, the following conversion factor was used to help in future comparisons and to facilitate the interpretation of results [41]:

$$
D=\exp (S W I)
$$

where $D$ stands for true diversity. Nonetheless, the model was adjusted in its entropy form. Surface runoff was measured in $8 \times 2 \mathrm{~m}^{2}$ plots, by collecting water flow in 200-liter recipients located in the lower part of the slope. Following Cerón-Bretón et al. [42], soil samples were taken to estimate ground carbon content. Aboveground carbon content was estimated through biomass equations for the main species in the area $[43,44]$. The estimated biomass was then converted into carbon content using carbon proportion data [44]. The total carbon content (ton/ha) was the sum of both aboveground and underground values. Finally, the net present value of residual standing trees refers to the difference in revenue between wood sales and production costs. The amount of wood sales was determined by multiplying the removed wood (after applying the silvicultural treatments) by the price at the main market point (Durango city). Production costs included wood extraction and its transportation, technical assistance, and site preparation. Cost information was provided by the owners of the property, updated to December 2017. A discount rate of $4.65 \%$ was used in calculations. A description of the data used and some statistics are shown in Table 1.

Each management objective required information on the level of the relative importance $(\lambda)$, according to all sectors involved in forest management. Information was taken from 29 surveys conducted on landowners, NGOs, and forest technicians, all of whom rated the objectives on a scale of 1 to 10. Individual group average preferences show that of the four ecosystem services evaluated here, tree diversity and water resource have a slightly higher importance level than the net present value and carbon content (Figure 3). The average values of the importance level $(\lambda)$ of all the sectors were used in Equations (4)-(6) to estimate the set of minimum distances from the efficient frontier to the ideal point. 
Table 1. Data description of the main variables used in the experimental plots in Molinillos, Durango.

\begin{tabular}{|c|c|c|c|c|}
\hline Variable & Mean & Minimum & Maximum & Std. Dev. \\
\hline Diameter $(\mathrm{cm})$ & 17.2 & 7.5 & 85.7 & 11.4 \\
\hline Height (m) & 10.0 & 0.3 & 30.0 & 5.5 \\
\hline Basal area $\left(\mathrm{m}^{2} / \mathrm{ha}\right)$ & 13.6 & 0.0 & 32.4 & 9.5 \\
\hline Annual growth $\left(\mathrm{m}^{3} / \mathrm{ha}\right)$ & 2.2 & 1.9 & 3.7 & 0.5 \\
\hline Age (years) & 53.5 & 39.0 & 69.0 & 9.2 \\
\hline Crown coverage $(\%)$ & 54.3 & 40.0 & 73.8 & 9.1 \\
\hline Volume $\left(\mathrm{m}^{3} / \mathrm{ha}\right)$ & 147.2 & 101.8 & 188.8 & 28.2 \\
\hline$\%$ Pine & 54.3 & 40.0 & 73.8 & 9.1 \\
\hline$\%$ Oak & 39.3 & 16.3 & 50.9 & 8.5 \\
\hline Elevation (m) & 2451 & 2366 & 2629 & 69.4 \\
\hline Slope (\%) & 41.3 & 10.0 & 66.0 & 13.8 \\
\hline Shannon Index & 1.27 & 0 & 2.07 & 1.3 \\
\hline True Diversity (number of species) & 3.5 & 0 & 8 & 3.7 \\
\hline Water surface runoff $(\mathrm{L} / \mathrm{ha})$ & 3051 & 243 & 18,660 & 3462 \\
\hline Carbon content (ton/ha) & 118.4 & 47.2 & 257.1 & 60.7 \\
\hline Net Present Value (Mex $\$ /$ ha) & 39,157 & 0 & 64,929 & 20,892 \\
\hline
\end{tabular}

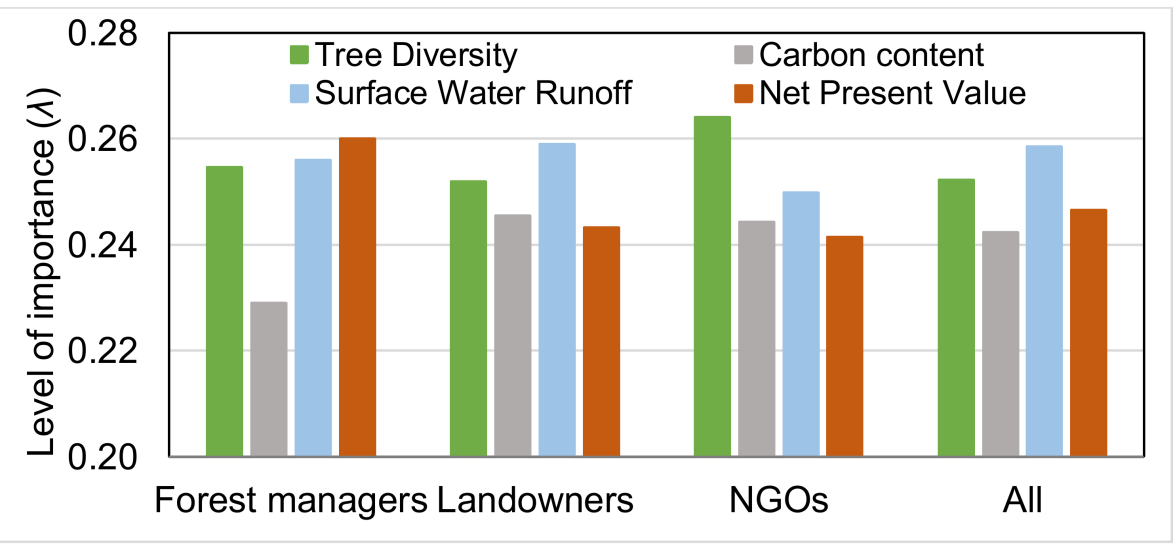

Figure 3. Level of importance of the ecosystem services according to forest managers, landowners, and NGOs. The level of importance has been normalized to make the sum equal to one (Source: Own information and [5]).

\subsection{Response Functions}

Data on the dasometric variables and management objectives were used to construct the response functions. These were created for the carbon content, surface runoff, net present value, and tree diversity. The relationship was constructed such that certain stand attributes, like basal area $(B A)$ or crown coverage $(C C)$, became the independent variables. These types of variables were selected because they can be manipulated by forest managers through silvicultural treatments. Other variables that were analyzed include standing volume $(V O L)$, arithmetic mean diameter $(M D)$, and average height (HGT). However, previous studies have shown a preference for residual $B A$ as the variable that measures a forest's density level and helps in setting a silvicultural treatment target [38]. As shown in the following equation, each one of the four ecosystem functions (ES) is a function of the different variables described above and the error factor, $\varepsilon$.

$$
E S=f(B A, V O L, M D, H G T, C C, \varepsilon),
$$

where $\varepsilon$ is the error.

\subsection{Sensitivity Analysis}

A sensitivity analysis was performed to test the resiliency of the solutions in respect to changes in both $p$ and the relative weight of the objectives $(\lambda)$. Since the process included the examination of 
various combinations of basal area, $p$, and $\lambda$ values, the Excel Solver ${ }^{\circledR}$ tool (Microsoft Corporation, Redmond, WA, USA) was used to evaluate the sensitivity of the solution. The first sensitivity analysis approach involved testing the resiliency of the compromise programming algorithm with changes in the $p$ values of 1,2 , and $\infty$. The second sensitivity analysis approach tested the stability of the solution with changes in the values of the preference structures assigned to each objective by the participating groups. Simulations were made with arbitrary variations. In one case, weights were assigned so that one objective dominated over the others, while in another case, an equal weight was assigned to each objective. Then, the simulated results were statistically tested to see if there were any significant differences among the results.

\section{Results}

Different linear and non-linear models were used to find the one with the best fit. They were tested to see which one of them best explained the relationship between an ecosystem service and the dasometric variables used, namely basal area, crown coverage, and volume. Previously, an exploration about the assumptions of linear models was made through normality and residual distribution tests. It was found that all the variables involved were acceptable for this type of analysis. In regard to the four management objectives, a collinearity diagnosis detected a high correlation among the independent variables of basal area, crown coverage, and volume (variance inflation factor > 7.6). Given that the basal area has demonstrated adequate applicability in similar studies [38,45], it was decided to use only this variable.

The usual regression parameters $\left(r^{2}, F\right.$ value, standard error) were used to evaluate the performance of the models and their coefficients. Since the Shannon-Wiener Index typically varies between 1.5 and 3.5 in natural ecosystems - and rarely exceeds the value of 5 [46] — a censored Tobit model was also used to regress tree diversity on basal area. These models, which represent $f_{i}$ in Equations (1) and (2), and their adjusted parameters, are shown in Table 2.

Table 2. Regression models and goodness-of-fit statistics of the ecosystem services evaluated in Molinillos, Durango.

\begin{tabular}{cccccc}
\hline Objective & Model * & Model Sig. & Adjusted $r^{2}$ & $\begin{array}{c}\text { Coefficients } \\
\text { (Std. Error) }\end{array}$ & $\begin{array}{c}\text { Coef. } \\
\text { Sig. }\end{array}$ \\
\hline Tree Diversity ** & $f_{T D}=b_{0}+b_{1} A B+b_{2} A B^{2}+\varepsilon$ & $<0.001$ & 0.48 & $\begin{array}{l}b_{0}=0.339(0.179) \\
b_{1}=0.154(0.026) \\
b_{2}=-0.0043(0.0008)\end{array}$ & $\begin{array}{c}0.07 \\
<0.01 \\
\end{array}$ \\
\hline $\begin{array}{c}\text { Surface runoff (L/ha) } \\
\text { Carbon Content } \\
\text { (ton/ha) }\end{array}$ & $f_{S W R}=b_{0} \exp \left(b_{1} \times A B\right)+\varepsilon$ & $<0.01$ & 0.57 & $\begin{array}{l}b_{1}=-0.062(0.013) \\
b_{0}=6130(688.7)\end{array}$ & $<0.01$ \\
\hline $\begin{array}{c}\text { Net Present Value } \\
\text { (\$/ha) }\end{array}$ & $f_{\mathrm{CO}_{2}}=b_{0} \exp \left(b_{1} \times A B\right)+\varepsilon$ & $<0.01$ & \multirow{2}{*}{0.94} & $\begin{array}{l}b_{1}=0.045(0.005) \\
b_{0}=58.91(7.41)\end{array}$ & $<0.01$ \\
\hline
\end{tabular}

${ }^{*}$ Basal area $(B A)$ is expressed in $\mathrm{m}^{2} /$ ha. ${ }^{* *}$ Based on Tobit model, which computes a pseudo $r^{2}$.

All the models had a good fit. For tree diversity, the Tobit model offered better results than the non-linear regression with the least squares method. The Tobit model was significant (prob $>\chi^{2}, 0.001$ ) with a log-likelihood value equal to -12.16 . Once the models were adjusted, a graph was constructed with the predicted values to demonstrate the trends of the four management objectives versus basal area (Figure 4).

Following Lee and Lautenbach [9], we used the sign of the Pearson correlation coefficient $(r)$ between ecosystem services to determine their type of relationships with basal area, which, as said before, can show synergy, trade-off, or no effect relationships. If the coefficient had significant values between -0.25 and 0.25 , then it was indicative of a no-effect relationship. However, if the coefficient was significantly greater than 0.25 , the relationship was identified according to the direction (+ for synergy or - for trade-off). Pearson correlations suggest a trade-off relationship between surface runoff 
and basal area $(r=-0.95$, sig. $<0.001)$ and a synergistic relationship between net present value and carbon content with basal area $(r=0.98$, sig. $<0.001 ; r=0.97$, sig. $<0.001$, respectively). Tree diversity has an apparent synergistic relationship in open forests, but a trade-off relationship in denser forests. In fact, there is a no-effect relationship in intermediate basal areas $\left(15-20 \mathrm{~m}^{2} / \mathrm{ha}\right)$. Once the type of relationship was examined, the next step was to find a $B A$ value (expressed in $\mathrm{m}^{2} /$ ha of the residual tree basal area) that simultaneously satisfies the management of the objectives being considered.

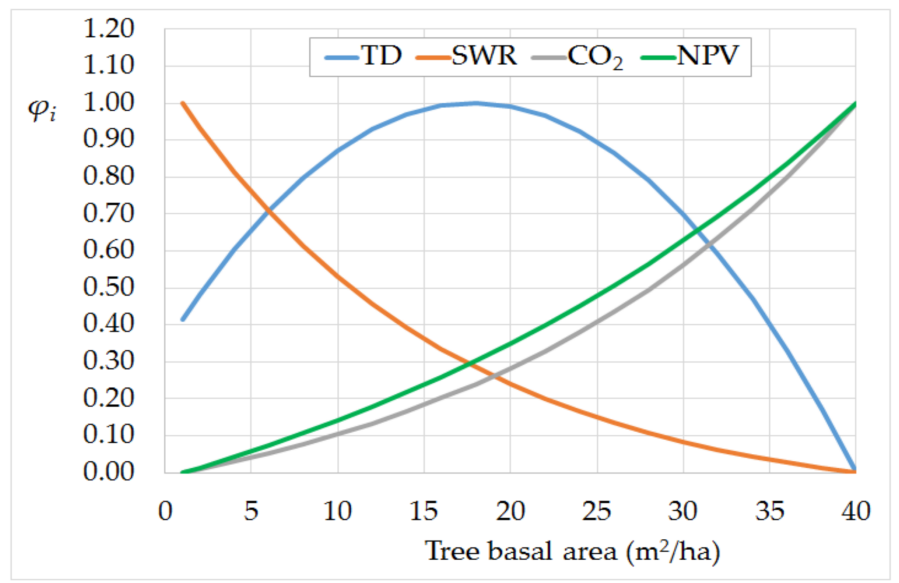

Figure 4. Normalized values of the objectives tree diversity (TD), surface water runoff (SWR), carbon content $\left(\mathrm{CO}_{2}\right)$, and net present value (NPV) according to the equations in Table 2.

\subsection{Multiobjective Decision-Making Analysis}

Compromise programming results indicate that the residual basal area slightly varies with the $p$ values used. When $p=1$, the most preferred solution tree basal area level is $17 \mathrm{~m}^{2} /$ ha. For $p=2$ and infinity, on the other hand, the most preferred basal area is $21 \mathrm{~m}^{2} /$ ha (Figure 5).

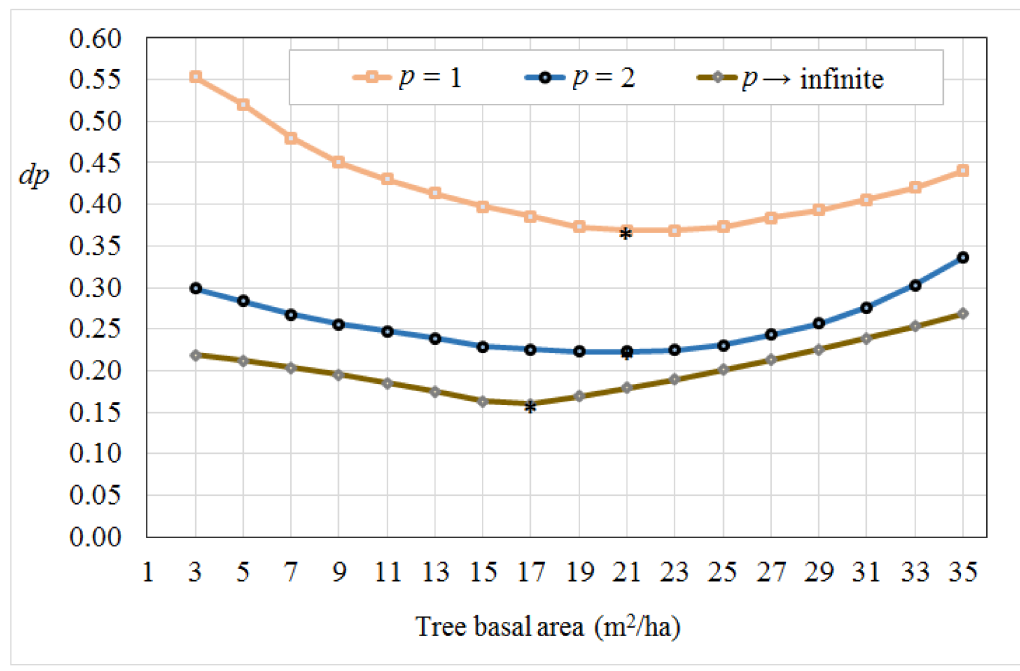

Figure 5. Results from the compromise programming model for the four ecosystem services evaluated. The asterisks represent the point with minimum distance between the efficient frontier and the ideal point.

According to the curves of $p$ values (Figure 5), it is evident that forests with low densities are not the preferred management levels for the four ecosystem services. Neither are denser forests because they would have limiting effects on the provision of other services, such as income maximization 
expressed in net present value. The most suitable basal area for the management of these ecosystem services (considering their relative importance and the opinion of stakeholders) is between 17 and $21 \mathrm{~m}^{2} / \mathrm{ha}$. In this range, the original values of the objectives were 127-152 tons/ha for carbon; 1.7-1.6 for tree diversity (or 5.5-5.3 species); 2137-1667 L/ha for surface runoff; and MEX \$41,962-47,123/ha for net present value.

\subsection{Sensitivity Analysis}

A sensitivity analysis helped us to evaluate the consistency of the solutions regarding potential changes in the parameters of the algorithm. This analysis was performed using the Excel Solver ${ }^{\circledR}$ tool, based on changes in $p$ and the level of importance of the objectives $(\lambda)$. As mentioned, in the case of the $p$ value, the values were 1,2 , and infinity. Some authors have suggested that the value of $p=2$ represents an average state in the deviations between the ideal point and the efficient frontier [29,37]. As a result, some recommend the use of this value in the solution approach $[34,38,45]$. Results indicate that the solution shows a similar tree basal area for $p$ values of 1 and $2\left(21 \mathrm{~m}^{2} / \mathrm{ha}\right)$, so the solution is not highly-sensitive to changes in the $p$ value (Figure 5). However, the algorithm does show some sensitivity when the solution changes to $17 \mathrm{~m}^{2} /$ ha for $p=\infty$. Considering the variation in risk aversion among decision-makers and the low difference in the result, we believe that a residual basal area between 17 to $21 \mathrm{~m}^{2}$ / ha is the most suitable for the management of these objectives.

Another sensitivity analysis was made to determine the impact of varying the levels of importance $(\lambda)$ given to the objectives on the final solution. The above results were based on the levels of importance each decision-maker originally gave to the objectives (Figure 3). However, after changing the weights of the objectives, it appears that the solution is sensitive to varying $\lambda$ values. The basal area increases to $28.3 \mathrm{~m}^{2}$ / ha when the majority of the relative weight is assigned to the carbon content and decreases to $8.83 \mathrm{~m}^{2} /$ ha when most of the weight is assigned to the net present value (NPV) (Table 3).

Table 3 indicates that the solutions are highly sensitive to changes in the relative importance given to the objectives, mainly in carbon content $\left(\mathrm{CO}_{2}\right)$ and net present value (NPV). Therefore, it is recommendable that similar weights like those in the original assignment be used to arrive at the most preferred forest treatment level. It is also recommendable to take some caution when reassessing the importance of the management objectives.

Table 3. Sensitivity analysis of the compromise solution to changes in the relative importance of management objectives. Bold numbers indicate the largest relative contribution (evaluation based on $p=2$ ).

\begin{tabular}{cccccc}
\hline \multirow{2}{*}{ Combination } & \multicolumn{4}{c}{ Importance of Management Objectives $(\boldsymbol{\lambda})$} & \multirow{2}{*}{ Basal Area $\left(\mathbf{m}^{\mathbf{2}} / \mathbf{h a}\right)$} \\
\cline { 2 - 5 } & TD & $\mathbf{C O}_{\mathbf{2}}$ & SWR & NPV & 20.3 \\
Original & 0.25 & 0.24 & 0.26 & 0.25 & 19.2 \\
1 & $\mathbf{0 . 4 0}$ & 0.20 & 0.20 & 0.20 & 28.3 \\
2 & 0.20 & $\mathbf{0 . 4 0}$ & 0.20 & 0.20 & 21.1 \\
3 & 0.20 & 0.20 & $\mathbf{0 . 4 0}$ & 0.20 & 8.8 \\
\hline
\end{tabular}

Note: TD stands for tree diversity, $\mathrm{CO}_{2}$ carbon content, SWR Surface water runoff, and NPV net present value.

\section{Discussion}

According to the MEA classification of ecosystem services [1], the four objectives in this study are classified as provisioning services (net present value, which results from timber production) and regulating services (surface run-off, carbon sequestration, and plant diversity). As stated before, the relationship between ecosystem services can be of synergy, trade-off, or no-effect type. In a meta-analysis study, Lee and Lautenbach [9] found that a synergistic relationship was dominant within regulating services, while a trade-off relationship exists between regulating and provisioning services. Our findings did not necessarily follow their conclusion. Within the regulating services group, there is a trade-off relationship (between carbon content and surface run-off) and a no-effect relationship (tree 
diversity and surface run-off). The link between regulating and provisioning services resulted in both synergy (carbon content vs. net present value) and trade-off (net present value vs. surface run-off).

Jackson et al. [47] reported substantial losses in stream flow (regulating service) with an increase in biomass (provisioning service), meaning a trade-off relationship. Note that more biomass leads to more amounts of $\mathrm{CO}_{2}$ sequestration, which also implies the existence of a trade-off relationship between carbon content and stream flow. Galicia and Zarco-Arista [48] showed various trade-off relationships between provisioning (timber production) and regulating services, namely water purification, soil retention, and landslide regulation. Differences among findings can be due to the type of management, the scale, and the sociological system found in the area [14,49]. A key implication of knowing the type of relationships between ecosystem services is to understand the complex processes that occur in nature and how humans intervene. Reducing undesired, and often unintentional, trade-offs while enhancing synergies among services is a shared goal that must be practiced $[9,14,23]$.

In addition, knowing the type of relationship between ecosystem services can help researchers understand the multi-functionality of forest ecosystems [48]. Management plans that attempt to maximize the production of one ecosystem service (i.e., timber) often result in substantial declines in the provision of other ecosystem services (i.e., water infiltration) [49]. Thus, the dominance of the traditional, single-objective forms of management that have characterized the forest management in many areas of the country [5] are no longer recommendable. Multiobjective decision-making is one tool that can deal with the multi-functionality of forests through the identification of the objectives and the perceptions of stakeholders [22].

However, the transition to multiobjective forest management is far from being an easy move. The findings of the study indicate that the preferred basal area $(B A)$ that can sustain the four management objectives ranges from 17 to $21 \mathrm{~m}^{2} /$ ha. The current average $B A$ found in the study area is $14.8 \mathrm{~m}^{2} /$ ha (median equal to $12.8 \mathrm{~m}^{2} / \mathrm{ha}$ ). Landowners would benefit from forest sites above the recommended $B A$. However, most areas (58\%) have a density level lower than the inferior limit, which means that they will remain unharvested until they exceed it. Our estimations indicate that this multiobjective management scheme represents up to $16 \%$ in economic losses due to timber reduction. Other studies have found more severe harm to forest conditions from such management. Keleş and Baskent showed that the total net present value of profits from timber and water production would be reduced by up to $25 \%$ when timber is incorporated into a multiobjective planning model [50]. However, the authors suggested that the social benefits of having a multiobjective management scheme should compensate the losses suffered by providing multiple ecosystem services to more sectors of society.

The results also indicated sensitivity to changes in the relative importance of management objectives. This actually represents a great opportunity for forest managers and landowners. Considering that each stand may have different management priorities (i.e., for timber, water flow, carbon sequestration, biodiversity uses, etc.), compromise programming is the most appropriate technique to provide the best solutions by incorporating stakeholders' preferences and stand attributes. Eventually, forest managers can prescribe the best silvicultural treatment level that best satisfies the management of the main services combined.

As we described the strengths of this study, it is important to mention a couple of concerns in the development of this research. First, the response functions need to be enriched with more data to allow more variations in topographic conditions, forest management regimes, climate, etc. The basis of our response functions relied on a few permanent plots that need to be multiplied. Continuing the establishment of permanent plots to assess the relationship between the ecosystem services and dasometric variables (such as basal area, crown coverage, volume, etc.) would be helpful. Second, since stakeholders' preferences change with time, it is recommended to update them in the same way as with the dasometric information. 


\section{Conclusions}

This study analyzed the interactions among four ecosystem services in northern Mexico. Pearson correlations and regression models were used to evaluate the interactions among tree diversity, carbon content, water surface runoff, and net present value as well as their relationships with basal area. The distance-based compromise programming technique, which has been successfully used to solve similar multiobjective forest resources management problems elsewhere, was successfully employed to determine a set of compromise solutions.

Results indicate that a trade-off relationship exists between surface runoff and basal area and a synergistic relationship between both net present value and carbon content with changes in basal area. Tree diversity has a synergistic relationship in open forests, but a trade-off relationship in denser forests. Knowledge of the type of relationships between ecosystem services helps with understanding the complex processes that occur in nature. Some trade-offs (i.e., surface runoff and basal area) could be reduced if more knowledge is available. For example, compromise programming can help with identifying the areas in which surface runoff is becoming critical due to lower forest density. Then, soil retention practices such as wood, rock, or silt-made fences can be recommended to reduce runoff.

Compromise programming results indicate that the best suitable residual basal area to sustain the combined management of these objectives varies between 17 and $21 \mathrm{~m}^{2} / \mathrm{ha}$. The compromise programming technique is a tool that can help with determining the most preferred density level that satisfies the management of various objectives simultaneously while considering the stakeholders' preferences. Moreover, it adapts to the management priorities of each forest stand.

We hope that demonstrating the application of this type of multiobjective analysis can cement transdisciplinary research strategies among Mexican resource managers, landowners, environmental groups, and other interested parties. Examples of such strategies would be the establishment of a network of permanent plots for the purpose of evaluating ecosystem services interactions, the co-funding of a monitoring system, and in general, the adoption of management schemes that integrate the complex multi-functionality of forest ecosystems. Given this complexity and the role of resource managers, it is important to revisit the dominance of the traditional, single-objective forest management approach.

Acknowledgments: We thank the owners of the Molinillos private estate for allowing us to establish the permanent plots and for the use of their forest inventory data and cartographic information. We are grateful to the editor of the journal, two anonymous reviewers, and Celina Perez for their invaluable comments. This work was supported by IPN (grant SIP 2017-1358), COCYTED y CONACYT. The research reported in this paper contributes to the Programme on Ecosystem Change and Society (www.pecs-science.org).

Author Contributions: G.P.-V. and J.C.M.-G. designed the study and performed the analysis; A.T. and M.P.-G. contributed to data analysis and interpretation. All authors participated in writing the paper.

Conflicts of Interest: The authors declare no conflict of interest.

\section{References}

1. MEA. Ecosystems and Human Well-Being: Synthesis. Millenium Ecosystem Assessment; World Resources Institute; Island Press: Washington, DC, USA, 2005.

2. De Groot, R.S.; Alkemade, R.; Braat, L.; Hein, L.; Willemen, L. Challenges in integrating the concept of ecosystem services and values in landscape planning, management and decision making. Ecol. Complex. 2010, 7, 260-272. [CrossRef]

3. Freeman, A.M. The measurement of environmental and resource values. In Theory and Methods; Resources for the Future Press: Washington, DC, USA, 2003.

4. Moreno-Sánchez, R.; Torres-Rojo, J.M. Decision support systems for forest management in Mexico: Their characteristics and context for their creation and evolution. In Decision Support Systems in Agriculture, Food and the Environment: Trends, Applications and Advances; IGI Global: Hershey, PA, USA, 2010; pp. 74-100.

5. Perez-Verdin, G.; Hernández-Diaz, J.C.; Márquez-Linares, M.A.; Tecle, A. Aplicación de técnicas multicriterio en el manejo integral forestal en Durango, México. Madera Bosques 2009, 15, 27-46. [CrossRef] 
6. Dueñez-Alanís, J.; Gutiérrez, J.; Pérez, L.; Návar, J. Manejo silvícola, capacidad de infiltración, escurrimiento superficial y erosión. Terra Latinoam. 2006, 24, 233-240.

7. Muñoz-Villers, L.E.; Holwerda, F.; Gómez-Cárdenas, M.; Equihua, M.; Asbjornsen, H.; Bruijnzeel, L.A.; Marín-Castro, B.E.; Tobón, C. Water balances of old-growth and regenerating montane cloud forests in central Veracruz, Mexico. J. Hydrol. 2012, 462, 53-66. [CrossRef]

8. Wolf, J.H.D. The response of epiphytes to anthropogenic disturbance of pine-oak forests in the highlands of Chiapas, Mexico. For. Ecol. Manag. 2005, 212, 376-393. [CrossRef]

9. Lee, H.; Lautenbach, S. A quantitative review of relationships between ecosystem services. Ecol. Indic. 2016, 66, 340-351. [CrossRef]

10. Haase, D.; Schwarz, N.; Strohbach, M.; Kroll, F.; Seppelt, R. Synergies, trade-offs, and losses of ecosystem services in urban regions: An integrated multiscale framework applied to the Leipzig-Halle region, Germany. Ecol. Soc. 2012, 17. [CrossRef]

11. Wagner, S.; Nocentini, S.; Huth, F.; Hoogstra-Klein, M. Forest management approaches for coping with the uncertainty of climate change: Trade-offs in service provisioning and adaptability. Ecol. Soc. 2014, 19. [CrossRef]

12. Howe, C.; Suich, H.; Vira, B.; Mace, G.M. Creating win-wins from trade-offs? Ecosystem services for human well-being: A meta-analysis of ecosystem service trade-offs and synergies in the real world. Glob. Environ. Chang. 2014, 28, 263-275. [CrossRef]

13. Zeleny, M. Multiple criteria decision making (MCDM): From paradigm lost to paradigm regained? J. Multi-Crit. Decis. Anal. 2011, 18, 77-89. [CrossRef]

14. Rodríguez, J.P.; Beard, T.D., Jr.; Bennett, E.M.; Cumming, G.S.; Cork, S.J.; Agard, J.; Dobson, A.P.; Peterson, G.D. Trade-offs across space, time, and ecosystem services. Ecol. Soc. 2006, 11. [CrossRef]

15. Von Gadow, K.; Kurttila, M.; Leskinen, P.; Leskinen, L.; Nuutinen, T.; Pukkala, T. Designing forested landscapes to provide multiple services. CAB Rev. 2007, 2. [CrossRef]

16. Zeleny, M. Multiple Criteria Decision Making; McGraw-Hill: New York, NY, USA, 1982.

17. Yu, P.L. A class of solutions for group decision problems. Manag. Sci. 1973, 19, 936-946. [CrossRef]

18. Martin, D.M.; Hermoso, V.; Pantus, F.; Olley, J.; Linke, S.; Poff, N.L. A proposed framework to systematically design and objectively evaluate non-dominated restoration tradeoffs for watershed planning and management. Ecol. Econ. 2016, 127, 146-155. [CrossRef]

19. Farley, J. Ecosystem services: The economics debate. Ecosyst. Serv. 2012, 1, 40-49. [CrossRef]

20. Nadrowski, K.; Wirth, C.; Scherer-Lorenzen, M. Is forest diversity driving ecosystem function and service? Curr. Opin. Environ. Sustain. 2010, 2, 75-79. [CrossRef]

21. Nelson, E.; Mendoza, G.; Regetz, J.; Polasky, S.; Tallis, H.; Cameron, D.R.; Chan, K.M.A.; Daily, G.C.; Goldstein, J.; Kareiva, P.M.; et al. Modeling multiple ecosystem services, biodiversity conservation, commodity production, and tradeoffs at landscape scales. Front. Ecol. Environ. 2009, 7, 4-11. [CrossRef]

22. Ananda, J.; Herath, G. A critical review of multi-criteria decision making methods with special reference to forest management and planning. Ecol. Econ. 2009, 68, 2535-2548. [CrossRef]

23. Duncker, P.S.; Raulund-Rasmussen, K.; Gundersen, P.; Katzensteiner, K.; De Jong, J.; Ravn, H.P.; Smith, M.; Eckmüllner, O.; Spiecker, H. How forest management affects ecosystem services, including timber production and economic return: Synergies and trade-offs. Ecol. Soc. 2012, 17. [CrossRef]

24. Kirchner, M.; Schmidt, J.; Kindermann, G.; Kulmer, V.; Mitter, H.; Prettenthaler, F.; Rüdisser, J.; Schauppenlehner, T.; Schönhart, M.; Strauss, F.; et al. Ecosystem services and economic development in Austrian agricultural landscapes-The impact of policy and climate change scenarios on trade-offs and synergies. Ecol. Econ. 2015, 109, 161-174. [CrossRef]

25. Brown, K.; Neil Adger, W.; Tompkins, E.; Bacon, P.; Shim, D.; Young, K. Trade-off analysis for marine protected area management. Ecol. Econ. 2001, 37, 417-434. [CrossRef]

26. Carpenter, S.R.; Group, M.E.A.S.W.; Assessment, M.E. Ecosystems and Human Well-Being: Scenarios: Findings of the Scenarios Working Group; Island Press: Washington, DC, USA, 2005.

27. Palacios-Agundez, I.; Fernández de Manuel, B.; Rodríguez-Loinaz, G.; Peña, L.; Ametzaga-Arregi, I.; Alday, J.G.; Casado-Arzuaga, I.; Madariaga, I.; Arana, X.; Onaindia, M. Integrating stakeholders' demands and scientific knowledge on ecosystem services in landscape planning. Landsc. Ecol. 2014, 29, 1423-1433. [CrossRef]

28. Horner, G.J.; Baker, P.J.; Nally, R.M.; Cunningham, S.C.; Thomson, J.R.; Hamilton, F. Forest structure, habitat and carbon benefits from thinning floodplain forests: Managing early stand density makes a difference. For. Ecol. Manag. 2010, 259, 286-293. [CrossRef] 
29. De Sousa Xavier, A.M.; Costa Freitas, M.d.B.; de Sousa Fragoso, R.M. Management of Mediterranean forests-A compromise programming approach considering different stakeholders and different objectives. For. Policy Econ. 2015, 57, 38-46. [CrossRef]

30. González-Elizondo, M.S.; González-Elizondo, M.; Tena-Flores, J.A.; Ruacho-González, L.; López-Enríquez, I. Vegetación de la sierra madre occidental, México: Una síntesis. Acta Bot. Mex. 2012, 100, 351-404. [CrossRef]

31. Perez-Verdin, G.; Cassian-Santos, J.M.; von Gadow, K.; Monarrez-Gonzalez, J.C. Molinillos private forest estate, Durango, Mexico. In Forest Plans of North America; Siry, J.P., Bettinger, P.S., Merry, K., Grebner, D.L., Boston, K., Cieszewski, C., Eds.; Academic Press Elsevier: San Diego, CA, USA, 2015; pp. 97-105.

32. Bagdon, B.A.; Huang, C.-H.; Dewhurst, S.; Meador, A.S. Climate change constrains the efficiency frontier when managing forests to reduce fire severity and maximize carbon storage. Ecol. Econ. 2017, 140, 201-214. [CrossRef]

33. Diaz-Balteiro, L.; Romero, C. Making forestry decisions with multiple criteria: A review and an assessment. For. Ecol. Manag. 2008, 255, 3222-3241. [CrossRef]

34. Estrella, R.; Cattrysse, D.; Van Orshoven, J. Comparison of three ideal point-based multi-criteria decision methods for afforestation planning. Forests 2014, 5, 3222-3240. [CrossRef]

35. Diaz-Balteiro, L.; González-Pachón, J.; Romero, C. Measuring systems sustainability with multi-criteria methods: A critical review. Eur. J. Oper. Res. 2017, 258, 607-616. [CrossRef]

36. Arenas Parra, M.; Bilbao Terol, A.; Pérez Gladish, B.; Rodríguez Uría, M.V. Solving a multiobjective possibilistic problem through compromise programming. Eur. J. Oper. Res. 2005, 164, 748-759. [CrossRef]

37. Krcmar, E.; van Kooten, G.C.; Vertinsky, I. Managing forest and marginal agricultural land for multiple tradeoffs: Compromising on economic, carbon and structural diversity objectives. Ecol. Model. 2005, 185, 451-468. [CrossRef]

38. Tecle, A.; Shrestha, B.P.; Duckstein, L. A multiobjective decision support system for multiresource forest management. Group Decis. Negot. 1998, 7, 23-40. [CrossRef]

39. Spellerberg, I.F.; Fedor, P.J. A tribute to Claude Shannon (1916-2001) and a plea for more rigorous use of species richness, species diversity and the 'Shannon-Wiener' index. Glob. Ecol. Biogeogr. 2003, 12, 177-179. [CrossRef]

40. Ramirez-Marcial, N.; González-Espinosa, M.; Williams-Linera, G. Anthropogenic disturbance and tree diversity in montane rain forests in Chiapas, Mexico. For. Ecol. Manag. 2001, 154, 311-326. [CrossRef]

41. Jost, L. Entropy and diversity. Oikos 2006, 113, 363-375. [CrossRef]

42. Cerón-Bretón, J.G.; Cerón-Bretón, R.M.; Rangel-marrón, M.M.; Muriel-García, M.; Cordova-Quiroz, A.V.; Estrella-Cahuich, A. Determination of carbon sequestration rate in soil of a mangrove forest in Campeche, Mexico. WSEAS Trans. Environ. Dev. 2011, 7, 54-64.

43. Návar, J. Allometric equations for tree species and carbon stocks for forests of northwestern Mexico. For. Ecol. Manag. 2009, 257, 427-434. [CrossRef]

44. Vargas-Larreta, B.; López-Sánchez, C.A.; Corral-Rivas, J.J.; López-Martínez, J.O.; Aguirre-Calderón, C.G.; Álvarez-González, J.G. Allometric equations for estimating biomass and carbon stocks in the temperate forests of north-western Mexico. Forests 2017, 8, 269. [CrossRef]

45. Poff, B.; Tecle, A.; Neary, D.G.; Geils, B. Compromise programming in forest management. J. Ariz.-Nev. Acad. Sci. 2010, 42, 44-60. [CrossRef]

46. Krebs, C.J. Ecological Methodology; Addison-Welsey Educational, Inc.: Menlo Park, CA, USA, 1999.

47. Jackson, R.B.; Jobbágy, E.G.; Avissar, R.; Roy, S.B.; Barrett, D.J.; Cook, C.W.; Farley, K.A.; le Maitre, D.C.; McCarl, B.A.; Murray, B.C. Trading water for carbon with biological carbon sequestration. Science 2005, 310, 1944-1947. [CrossRef] [PubMed]

48. Galicia, L.; Zarco-Arista, A.E. Multiple ecosystem services, possible trade-offs and synergies in a temperate forest ecosystem in Mexico: A review. Int. J. Biodivers. Sci. Ecosyst. Serv. Manag. 2014, 10, 275-288. [CrossRef]

49. Bennett, E.M.; Peterson, G.D.; Gordon, L.J. Understanding relationships among multiple ecosystem services. Ecol. Lett. 2009, 12, 1394-1404. [CrossRef] [PubMed]

50. Keleş, S.; Başkent, E.Z. Joint production of timber and water: A case study. Water Policy 2011, 13. [CrossRef]

(C) 2018 by the authors. Licensee MDPI, Basel, Switzerland. This article is an open access article distributed under the terms and conditions of the Creative Commons Attribution (CC BY) license (http://creativecommons.org/licenses/by/4.0/). 